\title{
The Effect of Multimedia Message Reminders on Oral Hygiene Promotion during Removable Orthodontic Treatment
}

\section{Tahereh Baherimoghadam}

Islamic Azad University Shiraz Branch

Navid Naseri (D Navidnaseri@gmail.com )

Islamic Azad University Shiraz Branch https://orcid.org/0000-0002-8772-5316

\section{Maliheh Mokhtar}

Islamic Azad University Shiraz Branch

\section{Shahram Hamedani}

Shiraz University of Medical Sciences

\section{Research article}

Keywords: Oral Hygiene, Text Message, Removable Orthodontics Treatment, Reminder Systems

Posted Date: August 10th, 2020

DOI: https://doi.org/10.21203/rs.3.rs-45868/v1

License: (c) (i) This work is licensed under a Creative Commons Attribution 4.0 International License. Read Full License 


\section{Abstract}

Background Orthodontic appliances complicate daily oral hygiene maintenance and enhance the formation of microbial biofilm on tooth surfaces and orthodontic appliances. Any tool that enhances the oral hygiene of patients during orthodontic treatment would be of imperative beneficial. This trial was conducted to assess the effect of message reminders on oral hygiene of patients during removable orthodontic treatment.

Methods In this 2-arm parallel randomized controlled trial, participants were randomly allocated to two groups; one receiving messages reminder and one as the control group. The patients in the messaging group received one or two message reminders and educational videos weekly during the course of treatment. The patients with removable maxillary appliance who were in the age range of 8 to 12 years old and had daily access to Internet to receive message reminders were recruited in this study. A single blinded examiner measured the plaque index $(\mathrm{PI})$, gingival index $(\mathrm{Gl})$ and dental caries index of patients in both groups at baseline (T0) and one (T1), three (T2) and six (T3) months after the first day of treatment to assess their oral hygiene status during the course of treatment in both groups.

Results A total of 50 patients were enrolled and randomized to two even groups $(n=25)$ but only 46 patients completed the study; 22 in control group, and 24 in message reminder group. The $\mathrm{PI}$ and GI scores were increased neither in control group nor in message reminder group during T0 and T1, significantly. The $\mathrm{PI}$ and $\mathrm{GI}$ scores in message reminder group were significantly lower than those in the control group at T2 (PI: $P=0.003, \mathrm{Gl}: P=0.001$ ) and T3 (PI: $P=0.044, \mathrm{Gl}: P=0.012)$. However, slight significant increasing in the $\mathrm{PI}$ and $\mathrm{Gl}$ score were found during T2 and T3 during in message reminder group. Caries index showed no significant difference between two group during study.

Conclusion It seems that message reminders can efficiently promote oral hygiene of patients undergoing removable orthodontic treatment. Although, this promotion wasn't progressive.

Trial registration: Iranian Registry of Clinical Trials (IRCT), IRCT20180923041092N2. Registered 25 July 2020 - Retrospectively registered, https://www.irct.ir/user/trial/47612.

\section{Background}

The maintenance of routine oral hygiene by patients is a crucial factor during orthodontic treatment. It is verified that there are challenges in patients adherence and compliance to sustained and acceptable oral hygiene during orthodontic treatments. ${ }^{1}$ Fixed and removable orthodontic appliances complicate daily oral hygiene routine and enhance the formation and accumulation of microbial biofilm on tooth surfaces, orthodontic brackets and wires, bands, springs, elastics and acrylic base plate. ${ }^{2-5}$ Biofilm accumulated on orthodontic appliances and tooth surfaces leads to gingival inflammation and dental caries. ${ }^{6-8}$

This microbial biofilm may impact the gingival health and cause dental caries. Gingival inflammation can negatively influence the periodontium and cause periodontal problems such as recession, pocket 
formation, gingival hyperplasia, and succeeding different periodontal diseases.

Moreover, poor oral hygiene negatively affects the quality of orthodontic treatment results; it can prolong the course of treatment or result in early cessation of orthodontic treatments. ${ }^{9,10}$ Several methods have been proposed for prediction of the ability of oral hygiene maintenance during the course of treatment. ${ }^{11-}$ ${ }^{13}$ One of the best models for this purpose is prediction of social behavior introduced by Aizen and Fishbein in 1980, which is referred to as the theory of reasoned action. ${ }^{14}$ This theory advocates that the behavior of individuals is influenced by their intention to present the behavior. Moreover, the intention of individuals is dependent on their attitude for that particular behavior and subjective paradigms. ${ }^{14}$ The theory of reasoned action can be regarded when the compliance of patients in maintaining their oral hygiene in orthodontic treatments is considered. From the first session, the patients are informed, instructed, and persuaded regarding the personal and social advantages of oral hygiene. However, after oral hygiene instruction, these patients usually do not receive reminders during their treatments. Thus, there is no promise that they fully adhere to oral hygiene instructions. With the help of text messaging and social media, it is easier to maintain a communication with the patients. The role of active reminders to improve attendance of patients, in-time medication intake, and behavioral change interventions has been documented in dental and medical literature. ${ }^{15-17}$ Positive change in behavior with regard to showing up for dental appointments by postal mail reminders, automatic phone reminders, and SMS has been reported; the efficacy of these systems has been confirmed. ${ }^{18-20}$ Moreover, it is verified that followup text messages sent from an orthodontic clinic after initial placement of orthodontic appliance resulted in lower self-reported pain score and decreased level of anxiety of their patients. ${ }^{21}$ Several studies have reported the positive effect of message reminders on oral hygiene during orthodontic treatment, ${ }^{22-25}$ however, these studies were enrolled on the patients who received fixed orthodontic treatments which are often performed after the age of twelve. To the best of authors' knowledge, the effect of message reminders on oral hygiene in younger patients using removable orthodontic appliances for treatment of dental or skeletal anomalies has not been evaluated. For oral hygiene evaluation different indices have been proposed; however, plaque index $(\mathrm{Pl})$ and gingival index $(\mathrm{Gl})$ are strong indices broadly used for assessment of oral hygiene and oral and dental health worldwide. ${ }^{22}$

\section{Specific objectives and hypotheses}

Hence, this study aimed to assess the effect of weekly message reminders to parents or legal guardians of children received removable orthodontic treatment on their oral hygiene by assessing $\mathrm{PI}, \mathrm{GI}$ and dental caries index. The null hypothesis of the study determines no difference in the mean of $\mathrm{Pl}, \mathrm{Gl}$ and dental caries index in patients who received message reminder compared to those not received.

\section{Methods}

\section{Trial design and any changes after trial commencement}


This study was a single-center; prospective 2-arm parallel randomized controlled trial with 1:1 allocation ratio. Ethical approval was granted from Ethics Committee of Islamic Azad University, Kazerun branch (IR.IAU.KAU.REC.1399.008) registered in the Iranian Registry of Clinical Trials (IRCT20180923041092N2). There were no changes to the trial after its commencement.

\section{Participants, eligibility criteria, and settings}

50 children with age range of 8 to 12 years referred to Department of Orthodontic, School of Dentistry, Shiraz Branch, Azad University (2018-2019) for removable orthodontic treatment were requested to participate in this study if they were willing to do so and did have access to WhatsApp application by smartphone. For the purpose of standardization, children whose treatment plan included the use of a removable orthodontic appliance made of auto-polymerizing acrylic resin with a midline screw and had a minimum treatment time of six months, and treated by the same orthodontist (N.N) were enrolled. The time of sending message reminder for each patients was determined with accordance to the time that parents were present at home. The patients who did not have daily access to Internet by their own smartphone or their parents, and patients who suffered from specific nutritional regimens, systemic diseases, syndromic anomalies such as cleft lip or palate and physical or mental disability were excluded from the study.

\section{Intervention}

The participants were divided randomly into two groups of message reminder and control. Both groups received adequate oral hygiene instructions at the beginning of the study. The patients in message reminder group received message reminders and videos as oral hygiene reminder while the control group did not receive any of these. Participants were not aware of the reason behind sending message reminders or the parameters evaluated in this study.

\section{Experimental group}

In the first phase (T1), the message reminders group received video and text messages containing information about the significance of oral hygiene twice a week for 4 weeks (Table 1). The message reminders were sent when both parents and patients were at home. The time interval between lunch and dinner was often chosen for most patients. For the rest of the patients, a convenient time was arranged following discussion with the parents. In the second phase (T2), patients received text message and educational videos for oral hygiene once a week for 2 months. In the third phase (T3), message reminders were sent to the message reminder group once a week for 3 months. Thereafter, $\mathrm{Pl}, \mathrm{Gl}$, and dental caries index were recorded at baseline (T0) and one (T1), three (T2) and six (T3) months after the first day of treatment by the same blinded examiner who did not have any information about participant's division in the two groups. 
Table 1

Text messages sent to the text messaging group

This text message is from the orthodontic clinic. We have to brush our teeth for a minimum of 3 minutes after each meal. Tooth brushing helps maintain sound beautiful teeth.

Hygienic alert! How long does your tooth brush take? 1-2 minutes? Each toothbrush has around 2500 bristles. Allow all of them to do their job and clean your teeth.

Your next appointment is soon. If you have forgotten to regularly brush your teeth, start now!

Did you know that after eyes, teeth have the greatest impact on facial beauty? Pay more attention to the health and appearance of your teeth!

Just wanted to remind tooth brushing after each meal! Do it and see the extraordinary result. See you soon!

You are approaching your next appointment fast! Keep up the good work! See you soon!

Please make time for tooth brushing. It significantly affects the outcome of orthodontic treatment.

A friendly reminder! Please do not forget to brush your teeth and clean the orthodontic appliance after each meal.

Your smile is the first thing noticed by others. It is your responsibility to keep your teeth clean and it is our responsibility to level and align them by orthodontic treatment.

\section{Control group}

The control group did not receive any text message or video during this period. The indices were measured at $\mathrm{T} 0$ (onset of study) and at the end of each phase (T1, T2 and T3) similar to message reminder group by the same blinded examiner .

\section{Outcomes (primary and secondary) and any changes after trial commencement}

The PI was measured using the Silness-Loe PI. ${ }^{26}$ For this purpose, presence of dental plaque was evaluated at four areas namely mesiobuccal, buccal, distobuccal and lingual of teeth \#44, 24, 32, 12,36 and 16, and each surface was given a score of 0 to 3 (Table 2). The GI was determined by assessing the degree of gingival inflammation around teeth \#44, 24, 32, 12, 36 and 16. As shown in Table 3 each surface was allocated a score of 0 to 3 . This index is used for assessment of the severity of gingival inflammation and its quantification. Bleeding on probing is an important criterion in this index. ${ }^{27}$ All teeth were examined for caries as shown in Table 4 and were allocated a score of 0 to 6 . Presence of caries was determined by clinical examination. ${ }^{28}$ 
Table 2

Plaque Index (PI)

\section{Score Presentation}

$0 \quad$ No plaque

1 A film of plaque adhering to the free gingival margin and adjacent area of the tooth. The plaque may be seen in situ only after application of disclosing solution or by using the probe on the tooth surface.

2 Moderate accumulation of soft deposit s within the gingival pocket, or the tooth and gingival margin which can be seen with the naked eye.

3 Abundance of soft matter within the gingival pocket and/or on the tooth and gingival margin.

Table 3

Gingival Index (GI)

\begin{tabular}{|ll|}
\hline Score & Presentation \\
\hline 0 & Normal gingiva, absence of inflammation, bleeding, or swelling \\
\hline 1 & Mild inflammation, slight edema and color change, but no bleeding \\
\hline 2 & Moderate inflammation, redness, swelling, and bleeding on probing \\
\hline 3 & Severe inflammation, marked redness, and edema, spontaneous bleeding \\
\hline
\end{tabular}

Table 4

The International Caries Detection and Assessment System (ICDAS)

\section{Score Presentation}

$0 \quad$ Sound

1 First Visual Change in Enamel (seen only after prolonged air drying or restricted to within the confines of a pit or fissure

2 Distinct Visual Change in Enamel

$3 \quad$ Localized Enamel Breakdown (without clinical visual signs of dentinal involvement)

$4 \quad$ Underlying Dark Shadow from Dentin

$5 \quad$ Distinct Cavity with Visible Dentin

$6 \quad$ Extensive Distinct Cavity with Visible Dentin

On the day of delivery of removable orthodontic appliance (TO), patients received a hygienic package including an Oral-B fluoridated toothpaste (with 1100 ppm fluoride) and a soft Trisa toothbrush (6+ years). Both groups received instructions on tooth brushing during the course of orthodontic treatment and recommendations regarding maintenance of orthodontic appliance. The modified Bass tooth brushing technique was taught to all patients. They were requested to brush each of the upper and lower 
dental arches for 2-3 minutes, three times a day. Also, patients received comprehensive information regarding dental plaque, dental calculus, and their effects on oral health.

No changes to the study design were made after commencement.

\section{Interim analyses and stopping guidelines}

Not applicable.

\section{Sample size selection \\ Randomization}

Participants were randomized according to the minimization method proposed by Pandis. ${ }^{29}$ Randomization ensured patients' allocation to both groups with 1:1 ratio. The first participant was allocated to one of group at random. For each subsequent participant, we determined that allocation to which group would lead to better balance between the groups in the variables of interest. Allocation concealment, and implementation were performed before randomization process by a researcher who was not involved in the study.

\section{Sample size calculation:}

A total of 40 participants were required to achieve $85 \%$ power (instituted by $\mathrm{G}$ power, version 3.0.1; Franz Faul universitat, Kiel, Germany) and detect significant differences considering the effect size of $0.47(P<$ 0.05). Considering the possible dropouts, the sample size was increased to 50.

\section{Blinding}

Examiner clinician, the person performing the data entry and the statistician were blinded to the intervention. It was not possible to blind the participants because the patients knew whether they had received the message reminder.

\section{Statistical analysis}

Data were analyzed using SPSS version 24. After descriptive analysis of the data, their normal distribution was evaluated using the Shapiro-Wilk test and Levene's test. Friedman test was used for intragroup comparisons of the mean $\mathrm{PI}$ and $\mathrm{Gl}$ in each group of the message reminder $\mathrm{g}$ and control groups among T0, T1, T2, and T3. The Wilcoxon Mann Whitney test was used to compare the mean PI and GI between the message reminder and control groups at each phase (T0, T1, T2 and T3).

The McNemar and Cochrane's tests were used for intra- group comparison of dental caries. The Pearson chi square test was applied to compare the two groups in terms of dental caries at each time point. Level of significance was set at 0.05 . The intraclass correlation coefficient (ICC) for measurement of $\mathrm{PI}, \mathrm{GI}$ and caries index was determined by assessing 10 randomly chosen participants within one hour at T0. ICC values $<0.20$ indicated poor agreement, values between $0.21-0.30$ indicated partial agreement, $0.31-$ 0.40 indicated fair agreement, $0.41-0.60$ indicated moderate agreement, $0.61-0.70$ indicated 
considerable agreement, $0.71-0.80$ indicated strong agreement, $0.81-0.90$ indicated almost complete agreement and 1 indicated complete agreement.

\section{Results}

\section{Participant flow}

50 Patients who met the eligibility criteria in 1:1 ratio were enrolled. Three patients from the control and one patients from the message reminder groups were excluded due to not showing up for the follow ups or fracture of appliance. Eventually, 46 patients successfully completed the study. A CONSORT diagram showing the flow of participants through the study is given in the Fig. 1.

\section{Baseline data}

The baseline characteristics for sex, age, and recruitment site in both groups were similar and are illustrated in Table 5.

Table 5

Baseline characteristics for patients in each group

\begin{tabular}{|lll|}
\hline & $\begin{array}{l}\text { Control group } \\
(\mathbf{n = 2 2})\end{array}$ & $\begin{array}{l}\text { Message reminder group } \\
(\mathbf{n}=\mathbf{2 4})\end{array}$ \\
\hline Mean age & $10.33 \pm 1.58$ & $9.79 \pm 1.40$ \\
Age category & $10(45.5 \%)$ & $14(58.3 \%)$ \\
$8-10$ & & $10(41.7 \%)$ \\
\hline $10-12$ & $12(54.5 \%)$ & \\
\hline Sex & & $10(41.7 \%)$ \\
\hline Boy & $9(40.9 \%)$ & $14(58.3 \%)$ \\
\hline Girl & $13(59.1 \%)$ & \\
\hline
\end{tabular}

\section{Numbers analyzed for each outcome, estimation and precision, subgroup analysis}

Plaque index

Comparison of message reminder and control groups revealed a significant difference in the mean $\mathrm{PI}$ at T2 $(P=0.003)$ and T3 $(P=0.044)$. The control group did not show significant increasing in $\mathrm{PI}$ score during study period. However, $\mathrm{PI}$ score in the message reminder group significantly decreased over the time from T0 to T2 $(P=0.003)$ and T0 to T3 $(P=0.042)$; and significantly increased from T2 to T3 $(P=0.014)$ (Table 6) (Fig. 2). 
Table 6

Comparison of plaque index at T0, T1, T2, and T3 between the control and Message reminder Group

\begin{tabular}{|c|c|c|c|c|c|}
\hline & Control Group & Message reminder Group & P-value & & \\
\hline $\mathrm{T}_{0}$ & $1.61(0.70)$ & $1.68(0.44)$ & 0.921 & & \\
\hline $\mathrm{T}_{1}$ & $1.73(0.77)$ & $1.66(0.63)$ & 0.225 & & \\
\hline $\mathrm{T}_{2}$ & $1.89(1.00)$ & $1.04(0.60)$ & $0.003 * *$ & & \\
\hline $\mathrm{T}_{3}$ & $1.82(0.78)$ & $1.25(0.76)$ & $0.044^{*}$ & & \\
\hline \multicolumn{6}{|c|}{ Control Group } \\
\hline $\mathrm{T}_{0} \mathrm{Vs}_{1} \mathrm{~T}_{1}$ & $\mathrm{~T}_{0} \mathrm{Vs} \mathrm{T}_{2}$ & $\mathrm{~T}_{0} \mathrm{Vs} \mathrm{T}_{3}$ & $\mathrm{~T}_{1} \mathrm{Vs} \mathrm{T}_{2}$ & $\mathrm{~T}_{1} \mathrm{Vs} \mathrm{T}_{3}$ & $\mathrm{~T}_{2} \mathrm{Vs}_{3}$ \\
\hline 0.821 & 0.076 & 0.065 & 0.722 & 0.521 & 0.618 \\
\hline \multicolumn{6}{|c|}{ Message reminder Group } \\
\hline $\mathrm{T}_{0} \mathrm{Vs}_{\mathrm{s}} \mathrm{T}_{1}$ & $\mathrm{~T}_{0} \mathrm{Vs}_{2}$ & $\mathrm{~T}_{0} \mathrm{Vs} \mathrm{T}_{3}$ & $\mathrm{~T}_{1} \mathrm{Vs} \mathrm{T}_{2}$ & $\mathrm{~T}_{1} \mathrm{Vs} \mathrm{T}_{3}$ & $\mathrm{~T}_{2} \mathrm{Vs}_{3}$ \\
\hline 0.067 & $0.003^{* *}$ & $0.042^{*}$ & 0.046 & 0.515 & $0.014^{\star}$ \\
\hline \multicolumn{6}{|c|}{$T_{0}$ to indicate baseline; $T_{1}$, after 1 month; $T_{2}$, after 3 months; $T_{3}$, after 6 months } \\
\hline \multicolumn{6}{|c|}{$\star P=.05 ; * \star P=.01 ; * \star \star P=.001 ; * \star \star \star P=.0001$} \\
\hline
\end{tabular}

Gingival Index

Significant differences in Gl score between message reminder and control groups was found at T2 ( $P=$ $0.001)$ and T3 $(P=0.012)$. Gl score in the message reminder group significantly decreased from T0 to T2 $(P=0.002)$, T0 to T3 $(P=0.043), \mathrm{T} 1$ to T2 $(\mathrm{P}=0.046))$; however significant increase in gingival index was observed during T2 to T3 $(P=0.031)$. In the control group, no significant change in $\mathrm{PI}$ was noted during the study period; except significant increase from T0 to T2 $(P=0.043)$ (Tables 7) (Fig. 3). 
Table 7

Comparison of gingival index at T0, T1, T2, and T3 between the control and Message reminder Groups

\begin{tabular}{|c|c|c|c|c|c|}
\hline & Control Group & Message reminder Group & P-value & & \\
\hline $\mathrm{T}_{0}$ & $0.71(0.50)$ & $0.73(0.49)$ & 0.254 & & \\
\hline $\mathrm{T}_{1}$ & $0.84(0.51)$ & $0.68(0.42)$ & 0.090 & & \\
\hline $\mathrm{T}_{2}$ & $0.79(0.52)$ & $0.38(0.37)$ & $0.001 * * *$ & & \\
\hline $\mathrm{T}_{3}$ & $0.95(0.61)$ & $0.62(0.41)$ & $0.012^{*}$ & & \\
\hline \multicolumn{6}{|c|}{ Control group } \\
\hline $\mathrm{T}_{0} \mathrm{Vs}_{1}$ & $\mathrm{~T}_{0} \mathrm{Vs} \mathrm{T}_{2}$ & $\mathrm{~T}_{0} \mathrm{Vs} \mathrm{T}_{3}$ & $\mathrm{~T}_{1} \mathrm{Vs} \mathrm{T}_{2}$ & $\mathrm{~T}_{1} \mathrm{Vs} \mathrm{T}_{3}$ & $\mathrm{~T}_{2} \mathrm{Vs}_{3}$ \\
\hline 0.428 & 0.090 & $0.043^{*}$ & 0.223 & 0.427 & 0.412 \\
\hline \multicolumn{6}{|c|}{ Message reminder Group } \\
\hline $\mathrm{T}_{0} \mathrm{Vs} \mathrm{T}_{1}$ & $\mathrm{~T}_{0} \mathrm{Vs} \mathrm{T}_{2}$ & $\mathrm{~T}_{0} \mathrm{Vs} \mathrm{T}_{3}$ & $\mathrm{~T}_{1} \mathrm{Vs} \mathrm{T}_{2}$ & $\mathrm{~T}_{1} \mathrm{Vs}_{3}$ & $\mathrm{~T}_{2} \mathrm{Vs} \mathrm{T}_{3}$ \\
\hline 0.075 & $0.002^{\star *}$ & $0.012^{*}$ & $0.046 *$ & 0.516 & $0.031 *$ \\
\hline \multicolumn{6}{|c|}{$T_{0}$ to indicate baseline; $T_{1}$, after 1 month; $T_{2}$, after 3 months; $T_{3}$, after 6 months } \\
\hline \multicolumn{6}{|c|}{$\star P=.05 ; * \star P=.01 ; * \star * P=.001 ; * \star \star \star P=.0001$} \\
\hline
\end{tabular}

Dental caries index

Table 8 shows no significant change in caries index during the study period in the message reminder and control groups $(P>0.05)$. The ICC was found to be $0.81-0.86$, which indicated complete agreement in measurements. 
Table 8

Comparison of caries index at T0, T1, T2, and T3 between the control and Message reminder Groups

\begin{tabular}{|c|c|c|c|c|c|}
\hline & Control Group & Message reminder Group & P-value & & \\
\hline $\mathrm{T}_{0}$ & 22 & 21 & 1.000 & & \\
\hline $\mathrm{T}_{1}$ & 22 & 21 & 1.000 & & \\
\hline $\mathrm{T}_{2}$ & 22 & 21 & 1.000 & & \\
\hline $\mathrm{T}_{3}$ & 22 & 22 & 0.550 & & \\
\hline \multicolumn{6}{|c|}{ Control group } \\
\hline $\mathrm{T}_{0} \mathrm{Vs}_{1}$ & $\mathrm{~T}_{0} \mathrm{Vs} \mathrm{T}_{2}$ & $\mathrm{~T}_{0} \mathrm{Vs} \mathrm{T}_{3}$ & $\mathrm{~T}_{1} \mathrm{Vs} \mathrm{T}_{2}$ & $\mathrm{~T}_{1} \mathrm{Vs}_{3}$ & $\mathrm{~T}_{2} \mathrm{Vs} \mathrm{T}_{3}$ \\
\hline 1.00 & 1.00 & 1.00 & 1.00 & 1.00 & 1.00 \\
\hline \multicolumn{6}{|c|}{ Message reminder Group } \\
\hline $\mathrm{T}_{0} \mathrm{Vs}_{1} \mathrm{~T}_{1}$ & $\mathrm{~T}_{0} \mathrm{Vs}_{2}$ & $\mathrm{~T}_{0} \mathrm{Vs}_{3}$ & $\mathrm{~T}_{1} \mathrm{Vs}_{2}$ & $\mathrm{~T}_{1} \mathrm{Vs} \mathrm{T}_{3}$ & $\mathrm{~T}_{2} \mathrm{Vs} \mathrm{T}_{3}$ \\
\hline 1.00 & 1.00 & 1.00 & 1.00 & 1.00 & 1.00 \\
\hline
\end{tabular}

\section{Harms}

No harm was observed or reported from the participants in the study.

\section{Discussion}

To the best of authors' knowledge, this study is the first randomized controlled trial to assess the effect of message reminders on oral hygiene status of children and adolescents between 8-12 years using removable orthodontic appliances. In the present study, minimization method was used for participant randomixation; minimization is a method of randomization used to ensure the balance of important prognostic factors among the groups and does not have the disadvantages of other randomization methods. List of randomization is not prepared in this method before the onset of study; instead, it is prepared in the process of selection of participants. It is a dynamic method of randomization. ${ }^{29}$

The effect of message reminders on oral hygiene was evaluated by measuring the $\mathrm{PI}, \mathrm{Gl}$ and caries index. The results showed that the message reminder group had significantly lower PI and GI at T2 (3 months after the onset of treatment) and T3 (6 months after the onset of treatment). However, no significant difference was found between the message reminder and control groups in PI or GI at T1 (one month 
after the onset of treatment). According to psychosocial studies, the mean time required for change of behavior to a habit is approximately 66 days. ${ }^{29}$ Thus, absence of a significant difference between the two groups at T1 may be due to inadequate time for formation of a new habit. ${ }^{29}$ Moreover, it has been shown that at the beginning of treatment, the conditions are very challenging for patients since they ought to get used to the new appliance and learn how to practice oral hygiene and clean the appliance. This explains the reason why at T1, challenges encountered by patients to get used to the appliance can result in insignificant effect of message reminders on $\mathrm{PI}$ and $\mathrm{Gl}$ compared to $\mathrm{T} 2$ in the two groups.

Previous studies revealed that orthodontic appliances complicate daily oral hygiene practice in patients ,which may lead to accumulation of dental plaque and microbial biofilm on tooth surfaces and orthodontic appliances. ${ }^{2-5}$ Nonetheless, the current results showed significant increase in $\mathrm{GI}$ in the control group between T0-T3 and no significant increase in PI during the course of study. This trend of change can be due to the fact that patients knew that they were participating in a study and this positively affected the behavior of patients in the control group with regard to oral hygiene. Oral hygiene instructions provided for both groups at the beginning of the study may have influenced the results accordingly.

Thus, significantly lower $\mathrm{PI}$ and $\mathrm{Gl}$ in the message reminder group at T2 and T3 is strong evidence supporting the positive effect of message reminder on oral hygiene status. The current results were in agreement with those of studies that reported the positive efficacy of message reminders for oral hygiene promotion of patients during fixed orthodontic treatment. ${ }^{22-25}$

Evidence shows that dental caries following orthodontic treatment can negatively affect the patients' perception of orthodontic treatment, which would negatively impact the future attendance of patients. ${ }^{22}$ Although initial enamel lesions may develop within 2-3 weeks following microbial plaque accumulation on tooth surfaces, ${ }^{31}$ the current study did not show any significant change in caries index in the two groups during the 6-month course of treatment and the two groups were the same in this respect. Eppright et al. ${ }^{22}$ suggested that studies on initial enamel lesions should follow-up patients for more than 6 months.

Several studies have evaluated the positive efficacy of SMS and email reminders for acceptance of orthodontic treatment by patients. ${ }^{22-25}$ In our study, the message reminder group showed a significant reduction in oral hygiene indices over time compared to the control group; although the trend of this reduction was not the same throughout the study. During T2-T3, a significant increase in $\mathrm{Pl}$ and $\mathrm{GI}$ was noted in the message reminder group. Significant increase in PI and GI in T3 can be due to the decreased impact of the "novelty effect"; the novelty effect is defined as initial improvement in performance in response to increased interest in new technology. ${ }^{20}$ Thus, after a while, the new technology, i.e. the SMS or email reminders would no longer have its initial novelty and attractiveness and gradually loses its efficacy. Although the current study was performed over a longer period of time (6 months) compared to 
previous studies, ${ }^{22-25}$ it appears that assessment of the long-term effects of reminders requires further studies.

Sending weekly text or multimedia messages to parents to remind their children to adhere to their oral hygiene protocol does not seem to a difficult task for a private office. At present, several communication companies provide services with regard to automatic sending of message reminders and many of such services are available free of charge in the Web. Moreover, particular applications in smartphones can be used as reminders. Providing such services would strengthen the communication between orthodontists and patients and indicate that the orthodontists are concerned about each and every one of their patients. Such behaviors can positively affect the patient satisfaction as well.

\section{Generalizability}

The generalizability of these results might be limited to 8 to 12 years old children with removable orthodontic appliance.

\section{Limitation}

This study was a single-center study; a multi-centric study would increase the sample in a shorter period and would increase validation of results. In this study, we used just clinical indices to determine oral hygiene status, further studies with microbial evaluation of acrylic base plate can be useful.

\section{Conclusion}

Sending message reminders and educational videos to parents emphasizing the significance of oral hygiene maintenance is an efficient method to promote oral hygiene status of orthodontic patients.Moreover, orthodontists can use an active reminder system to increase patient cooperation during orthodontic treatment.

\section{Abbreviations}

PI:Plaque Index; GI:Gingival Index; Intraclass Correlation Coefficient:ICC.

\section{Declarations}

- Ethics approval and consent to participate: Ethical approval to conduct the study was granted by the Medical Ethics Committee, Shiraz branch, Islamic Azad university, Iran (IAU.KAU.REC.1399.008) and registered in the Iranian Registry of Clinical Trials (IRCT20180923041092N2). Written Informed consents were obtained from parents or guardians for participants under 16 years old.

- Consent for publication: Not applicable

- Availability of data and material: The datasets used and/or analyzed during the present study are available from the corresponding author upon request. 
- Competing interests: The authors declare that they have no competing interests.

- Funding: No funding was provided for this study.

- Authors' contributions: NN and TBM contributed in the design of the study, wrote the first draft of the manuscript, revised the manuscript, participated in data interpretation, and gained permission from the Medical Ethics Committee, Shiraz branch, Islamic Azad university, Iran. MM and NN participated in acquisition of data. SH was major contributor in writing and revising of the manuscript, participated in data interpretation, and provided critical comments. All authors read and approved the final manuscript.

- Acknowledgements: The authors thank to all study participants for providing data for this study.

\section{References}

1. -Cardoso-Silva C, Barbería E, Ramos Atance JA, Maroto M, Herna'ndez A, Garci'a-Godoy F. Microbiological analysis of gingivitis in pediatric patients under orthodontic treatment. Eur J Paediatr Dent. 2011;12:210-14.

2. -Anhoury P, Nathanson D, Hughes CV, Socransky S, Feres M, Chou LL. Microbial profile on metallic and ceramic bracket materials. Angle Orthod. 2002;72(4):338-43.

3. -Leung NM, Chen R, Rudney JD. Oral bacteria in plaque and invading buccal cells of young orthodontic patients. Am J Orthod Dentofacial Orthop. 2006;130(6):698.e11-8.

4. -Steinberg D, Eyal S. Initial biofilm formation of Streptococcus sobrinus on various orthodonticsappliances. J Oral Rehabil. 2004;31(11):1041-5.

5. -Ahn SJ, Lim BS, Lee YK, Nahm DS. Quantitative determination of adhesion patterns of cariogenic streptococci to various orthodontic adhesives. Angle Orthod. 2006;76(5):869-75.

6. -Chapman JA, Roberts WE, Eckert GJ, Kula KS, González-Cabezas C. Risk factors for incidence and severity of white spot lesions during treatment with fixed orthodontic appliances. Am J Orthod Dentofacial Orthop. 2010;138(2):188-94.

7. -Hadler-Olsen S, Sandvik K, El-Agroudi MA, Øgaard B. The incidence of caries and white spot lesions in orthodontically treated adolescents with a comprehensive caries prophylactic regimen-a prospective study. Eur J Orthod. 2012;34(5):633-9.

8. -Shungin D, Olsson Al, Persson M. Orthodontic treatment-related white spot lesions: a 14-year prospective quantitative follow-up, including bonding material assessment. Am J Orthod Dentofacial Orthop. 2010;138(2):e1-8.

9. -Beckwith FR, Ackerman RJ Jr, Cobb CM, Tira DE. An evaluation of factors affecting duration of orthodontic treatment. Am J Orthod Dentofacial Orthop. 1999;115(4):439-47.

10. -Skidmore KJ, Brook KJ, Thomson WM, Harding WJ. Factors influencing treatment time in orthodontic patients. Am J Orthod Dentofacial Orthop. 2006;129(2):230-8.

11. -Richter DD, Nanda RS, Sinha PK, Smith DW, Currier GF. Effect of behavior modification on patient compliance in orthodontics. Angle Orthod. 1998;68(2):123-32. 
12. -Sinha PK, Nanda RS, McNeil DW. Perceived orthodontist behaviors that predict patient satisfaction, orthodontist-patient relationship, and patient adherence in orthodontic treatment. Am J Orthod Dentofacial Orthop. 1996;110(4):370-7.

13. -Feil PH, Grauer JS, Gadbury-Amyot CC, Kula K, Mc Cunniff MD. Intentional use of the Hawthorne effect to improve oral hygiene compliance in orthodontic patients. J Dent Educ. 2002;66(10):112935.

14. -Ajzen I, Fishbein M. Understanding Attitudes and Predicting Social behavior. Englewood Cliffs: Prentice-Hall; 1980.

15. -Almog DM, Devries JA, Borrelli JA, Kopycka-Kedzierawski DT. The reduction of broken appointment rates through an automated appointment confirmation system. J Dent Educ. 2003;67(9):1016-22.

16. -Roth J, Kula T, Claros A, Kula K. Effect of a Computer-Generated telephone reminder system on appointment attendance. Semin Orthod. 2004;10:190-3.

17. -Fjeldsoe BS, Marshall AL, Miller YD. Behavior change interventions delivered by mobile telephone short-message service. Am J Prev Med. 2009;36(2):165-73.

18. -Hussein WI, Hasan K, Jaradat AA. Effectiveness of mobile phone short message service on diabetes mellitus management; the SMS-DM study. Diabetes Res Clin Pract. 2011 Oct;94(1):e24-6.

19. -Cole-Lewis $\mathrm{H}$, Kershaw T. Text messaging as a tool for behavior change in disease prevention and management. Epidemiol Rev. 2010;32:56-69.

20. -Can S, Macfarlane T, O'Brien KD. The use of postal reminders to reduce non-attendance at an orthodontic clinic: a randomized controlled trial. Br Dent J. 2003;195(4):199-201.

21. -Keith DJ, Rinchuse DJ, Kennedy M, Zullo T. Effect of text message follow-up on patient's selfreported level of pain and anxiety. Angle Orthod. 2013;83(4):605-10.

22. -Eppright M, Shroff B, Best AM, Barcoma E, Lindauer SJ. Influence of active reminders on oral hygiene compliance in orthodontic patients. Angle Orthod. 2014;84(2):208-13.

23. -Zotti F, Dalessandri D, Salgarello S, Piancino M, Bonetti S. Visconti L,Paganelli C.Usefulness of an app in improving oral hygiene compliance in adolescent orthodontic patients. Angle Orthod. 2016;86(1):101-7.

24. -Bowen TB, Rinchuse DJ, Zullo T, DeMaria ME. The influence of text messaging on oral hygiene effectiveness. Angle Orthod. 2015;85(4):543-8. ..

25. -Abdaljawwad A. The Influence of Text Message Reminders on Oral Hygiene Compliance in Orthodontic Patients. Iraqi Dent J. 2016;38(1):58-62.

26. -Löe H. The Gingival Index, the Plaque Index and the Retention Index Systems. J Periodontol. 1967;38(6):610-6.

27. -Silness J, Loe H. Periodontal Disease in Pregnancy. Ii. Correlation Between Oral Hygiene and Periodontal Condition. Acta Odontol Scand. 1964;22:121-35.

28. Gugnani -Neeraj, Pandit IK, Srivastava N, Gupta M, Sharma M. International Caries Detection and Assessment System (ICDAS): A New Concept. Int J Clin Pediatr Dent. 201;4(2):93-100. 
29. -Pandis N. Randomization. Part 2: Minimization. Am J Orthod Dentofacial Orthop. 2011;140(6):9024.

30. -Lally P, Van Jaarsveld C, Potts $\mathrm{H}$, Wardle J. How are habits formed: Modelling habit formation in the real world. Eur J Soc Psychol. 2010;40:998-1009.

31. -Lundström F, Krasse B. Caries incidence in orthodontic patients with high levels of Streptococcus mutans. Eur J Orthod. 1987;9:117-21.

Figures 


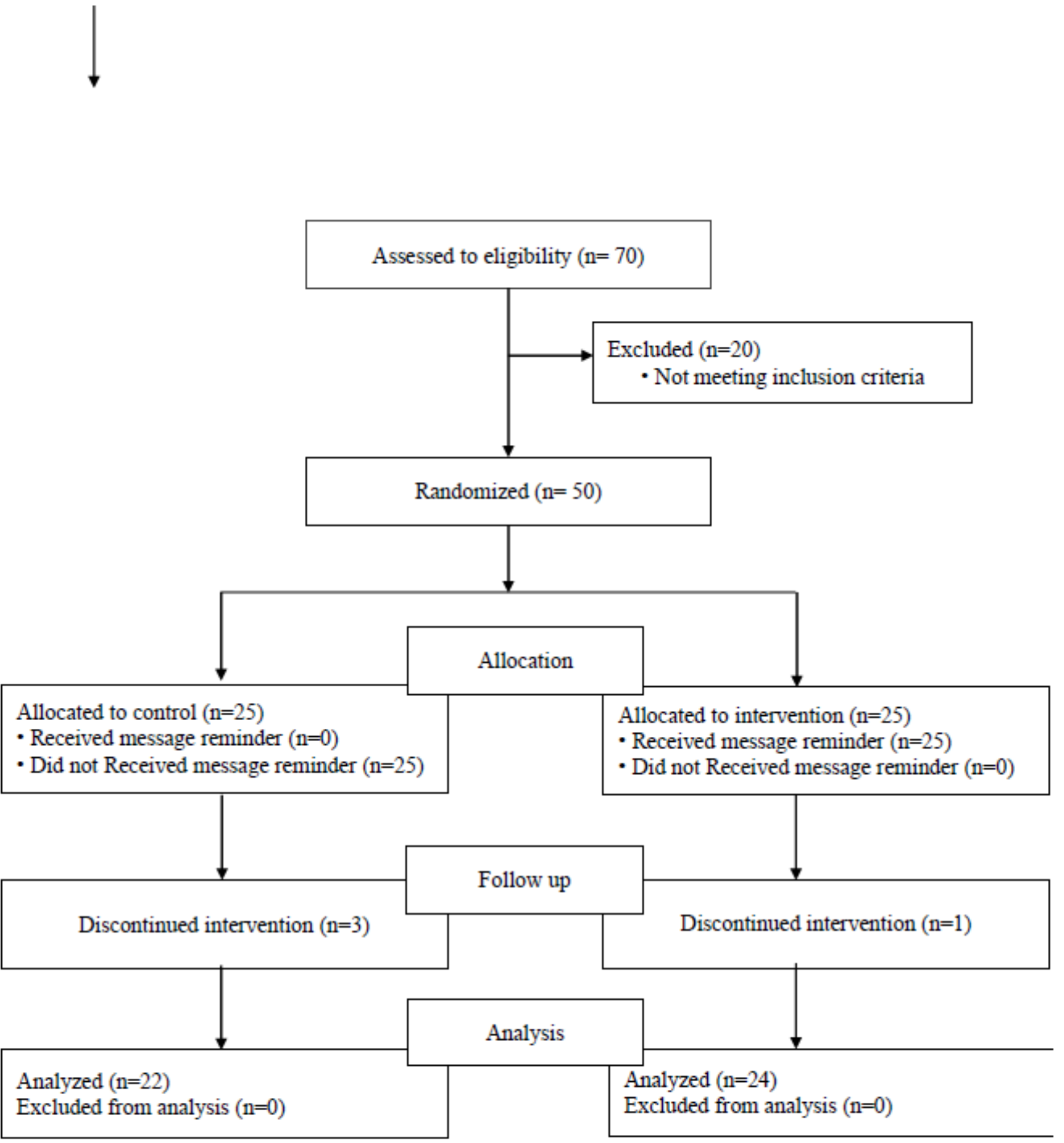

\section{Figure 1}

CONSORT diagram showing the flow of participants through the study. 


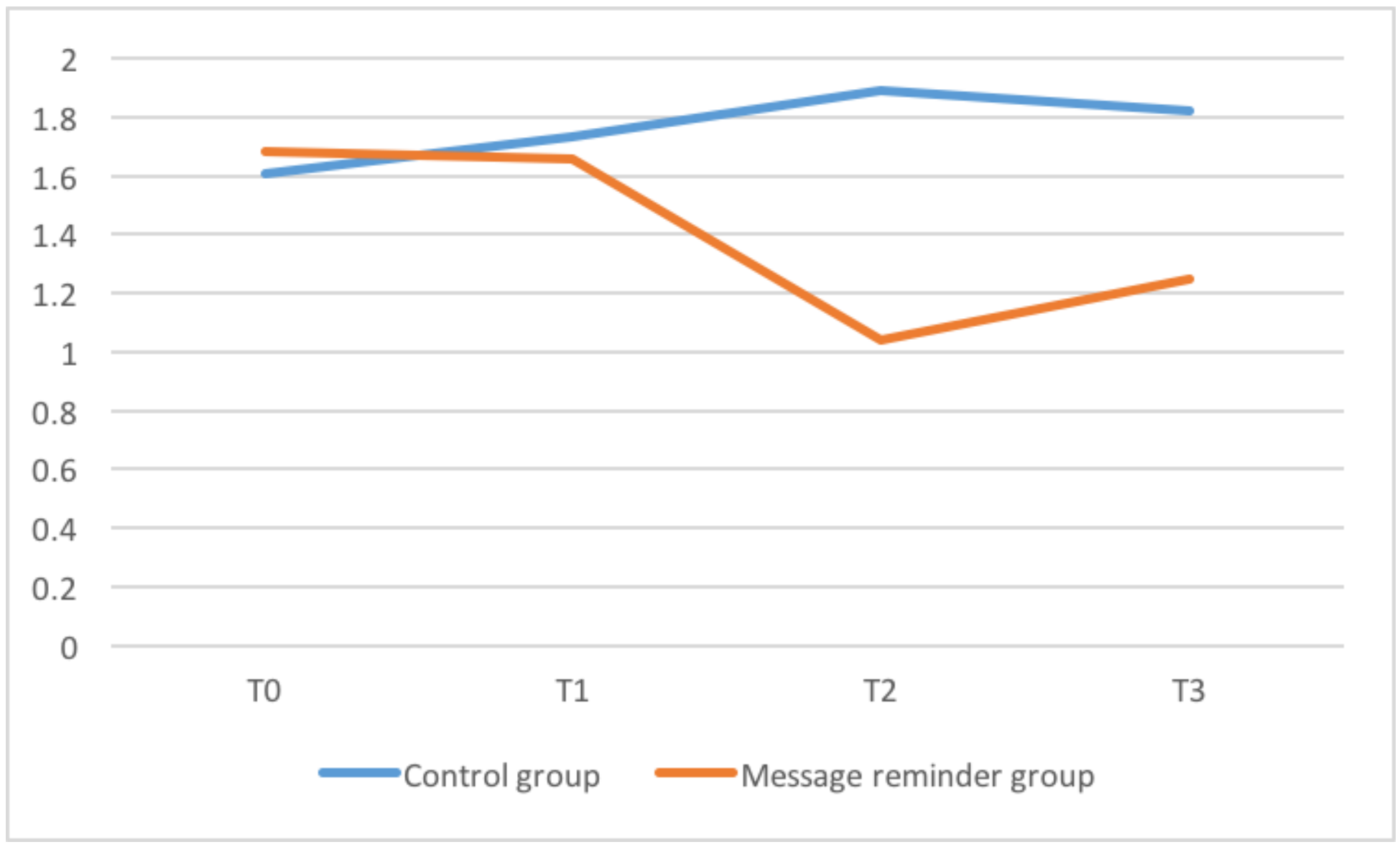

Figure 2

PI score trend during T0 to T3 


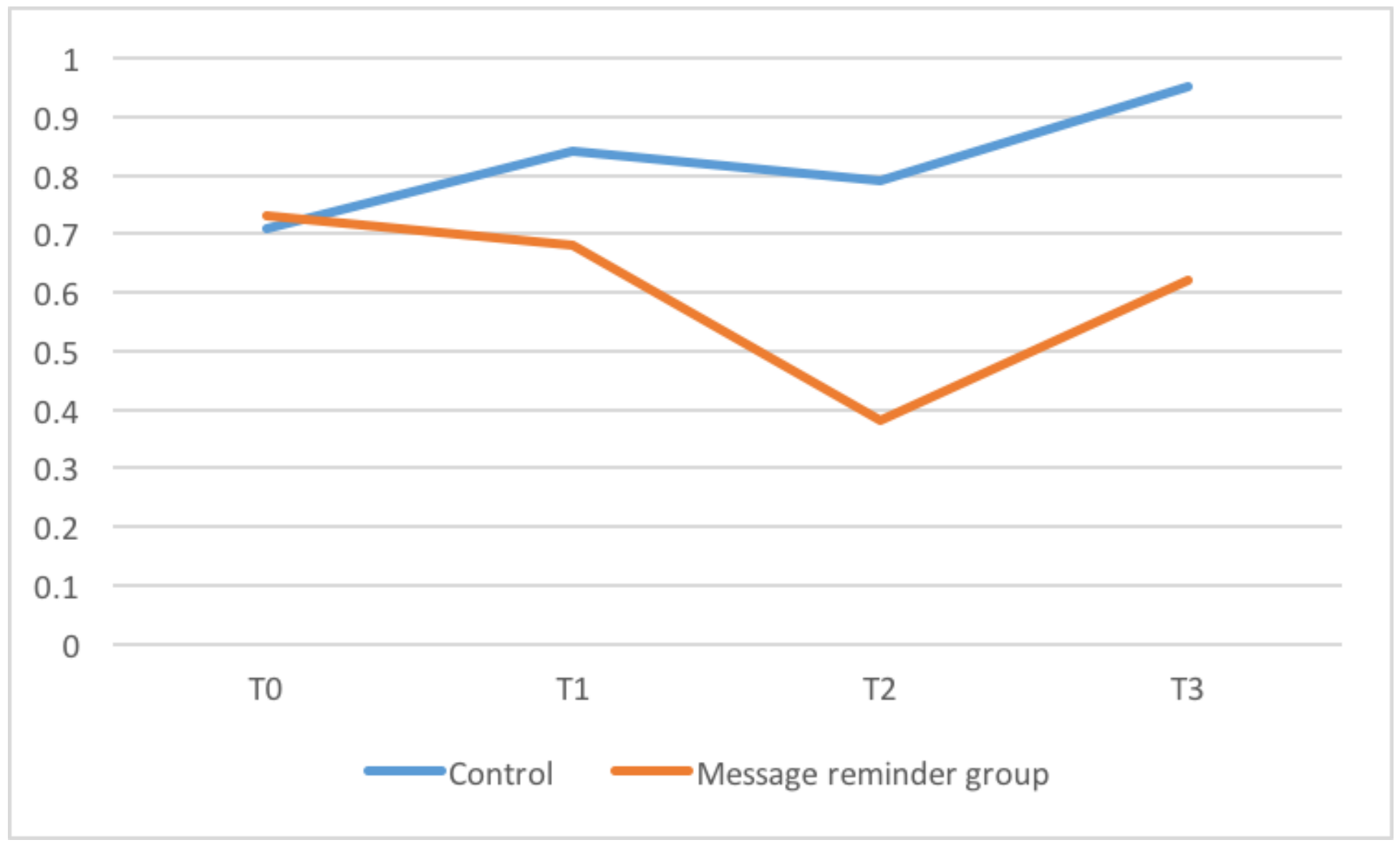

Figure 3

Gl score trend during $\mathrm{T} 0$ to $\mathrm{T} 3$ 